\title{
Crystal Structure of Protic lonic Liquids and their hydrates
}

\author{
M. P. Hassett ${ }^{1}$, H. Brand ${ }^{2}$, J. Binns ${ }^{1}$, A. V. Martin ${ }^{1}$, T. L. Greaves ${ }^{1}$ \\ ${ }^{1}$ School of Science, RMIT University, Melbourne, Victoria 3000, Australia, ${ }^{2}$ Australian Nuclear Science and Technology \\ Organisation, Australian Synchrotron, Victoria 3168, Australia
}

\section{S3717891@student.rmit.edu.au}

Protic Ionic Liquids (PILs) are a class of tailorable solvents made up of fused salts with melting points below $100{ }^{\circ} \mathrm{C}$, which are formed through a Brønsted acid-base reaction involving proton exchange[1]. These solvents have applications as lubricants, electrolytes, and many other uses[2]. Although they are quite similar to molten salts, their crystal structures have not been explored indepth, with only ethylammonium nitrate (EAN) having a reported crystal structure[3, 4].

Ten alkylammonium-based protic ionic liquids at both neat ( $<1 \mathrm{wt} \%$ water) and $90 \mathrm{~mol} \% \mathrm{PIL}, 10 \mathrm{~mol} \%$ water concentrations were selected. Diffraction patterns were collected at the Australian Synchrotron ANSTO while attempting to crystallise the samples by cooling to $120 \mathrm{~K}$. Five samples crystallised ( 3 neat, 2 dilute), where the temperature of the system was then increased at a rate of 6 $\mathrm{K} / \mathrm{min}$ to room temperature. From these patterns we have identified a number of crystal phases, identifying their stability ranges and lattice constant variation from $120 \mathrm{~K}$ to room temperature.

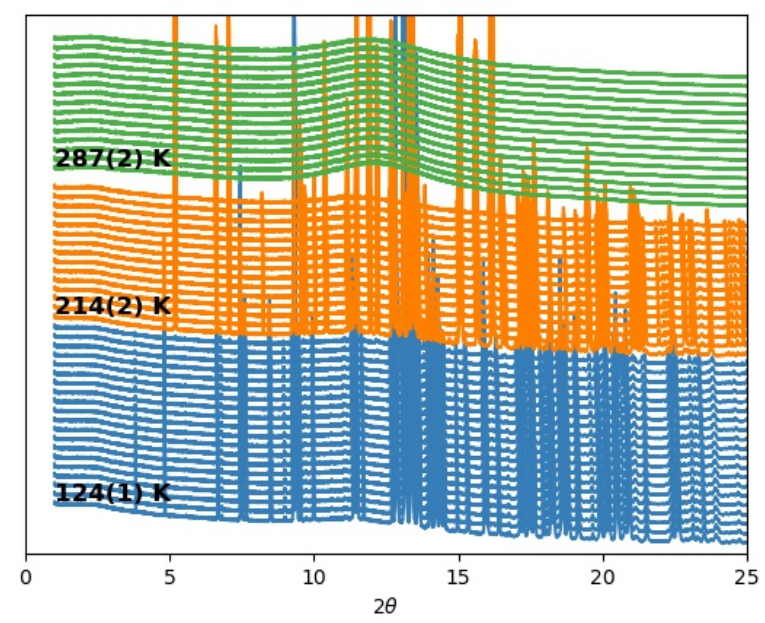

Figure 1. Waterfall plot of ethylammonium nitrate (EAN) crystal phase structure with increasing temperature. Three phases are visible: $\alpha$-crystal in blue, $\beta$-crystal in orange, and liquid phase in green.

[1] Hallett, J.P. and Welton, T. (2011). Chemical Reviews. 111, 3508-3576.

[2] Greaves, T.L. and Drummond, C.J. (2008). Chemical Reviews. 108, 206-237.

[3] Abe, H. (2020). Journal of Molecular Liquids. 6.

[4] Henderson, W.A., et al. (2012). Physical Chemistry Chemical Physics. 14, 16041.

Keywords: protic ionic liquids; crystal phases; crystal structures 